\title{
Use of Holmium YAG laser in circumcision: a novel, less complicated and alternative procedure for adolescent
}

Pei-Lin Huang ${ }^{1,2+}$, I-Ching Lee ${ }^{1,2+}$, De-Chan Tsai ${ }^{1,2}$, Jen-Ho Tsai ${ }^{2}$, Vincent F. S. Tsai ${ }^{1,2}$ and Yuan-Hung Pong ${ }^{1,2^{*}}$

\begin{abstract}
Background: To evaluate the efficacy and safety of Holmium YAG laser circumcision in adolescents.

Methods: Eighty-one patients underwent circumcision for medical reasons, and patients' requests were collected retrospectively during February 2017 to February 2019. They were divided into two groups: Holmium YAG laser (group $1, n=41$ ) and conventional group (group $2, n=40$ ). The guillotine method with a Holmium YAG laser was applied for circumcisions, and all the procedures were performed by a single urologist who was well-experienced with circumcision practices.

Results: The average age of group 1 was $15.53 \pm 7.35$ years old, and the average age was $16.34 \pm 9.22$ years old in group 2. There was no significant difference in age and indications. The average operative time was significantly shorter in group 1 than in group 2 ( $24.40 \pm 3.94$ vs. $27.25 \pm 4.35 \mathrm{~min}, p<0.01)$. The estimated blood loss was less in group 1 compared to group 2. There were fewer complications in group 1 than in group $2(3 / 41 \mathrm{vs} .10 / 40, p<0.01)$ and patients also felt less pain in group $1(p<0.01)$. All patients tolerated this procedure without severe side effects.

Conclusions: The use of Holmium YAG laser in circumcision is a novel, less complicated, easy, and less painful alternative procedure for circumcision in young males.
\end{abstract}

Keywords: Circumcision, Laser, Holmium YAG, Adolescent, Less complicated

\section{Background}

Circumcision is a common procedure in penile surgery. It can be performed using several methods and materials, including a conventional scalpel or laser technique [1, 2]. The benefits of using a laser in circumcision include accurate cutting, hemostasis, and less tissue damage and pain [3, 4]. Currently, the most commonly used types of lasers are carbon dioxide $\left(\mathrm{CO}_{2}\right)$ lasers and neodymium: yttrium-aluminum-garnet (Nd-YAG) lasers. It is thought that these devices enable dry incisions and minimal tissue damage $[5,6]$. Our department first introduced the Holmium YAG laser for circumcision. However, there

\footnotetext{
*Correspondence: pong9101095@yahoo.com.tw

${ }^{\dagger}$ Pei-Lin Huang and I-Ching Lee have contributed equally to this work

${ }^{1}$ Department of Urology, Ten Chen Hospital, Taoyuan, Taiwan, ROC
}

Full list of author information is available at the end of the article was no documentation for this method. The aim of this study was to present the efficacy and safety of the Holmium YAG laser for circumcision. Hence, it may result in more widespread use for circumcision.

\section{Methods}

The medical records of 81 patients who underwent circumcision for medical reasons and patients' requests were collected retrospectively during February 2017 to February 2019. Patients aged from 6 years old to 30 years old who were diagnosed with phimosis, redundant prepuce, or recurrent balanoposthitis were included in this study. Forty patients who underwent circumcision with the conventional scalpel method, and 41 patients who underwent circumcision with a Holmium YAG laser were included. The exclusion criteria were active genital infections, severe adhesion of the prepuce and glans, anatomic 
abnormalities of the penis, and paraphimosis or trauma. The following parameters were recorded according to chart reviews, medical records, or telephone interviews: operating time, estimated blood loss, postoperative pain, and operation-related complications. A visual analog scale (VAS) was applied to evaluate postoperative pain the day after surgery. Subjects reported VAS pain scores by making a handwritten mark on a $10-\mathrm{cm}$ line that represented a continuum between "no pain, zero-score" and "worst pain, 10 score."

The data were expressed as the mean \pm standard deviation. Statistical analysis of qualitative variables was performed using the Wilcoxon signed rank test, and quantitative variables were analyzed with Student's $t$ test and Pearson's Chi-squared test. A $p$ value of $<0.05$ was considered significant. Data were analyzed on a personal computer using commercially available software (SPSS Version 21.0, SPSS Inc, Chicago, IL; IBM Corporation).

\subsection{Operative technique: guillotine method}

All procedures were performed under a penile root regional block anesthesia using $1 \%$ lidocaine. Circumcision was performed by a single urologist who was wellexperienced with circumcision practices. After good sterilization with beta-iodine, adequate separation of the prepuce and glans was confirmed. First, the foreskin was totally released from the glans, mosquito forceps were applied to the tip of the foreskin ventrally and dorsally, and the foreskin was protracted. The long-straight forceps were applied along the lower foreskin above the glans. The foreskin was excised by cutting below the forceps with a Holmium YAG laser (Group 1, $n=41$ ). The Holmium YAG laser pulse duration was set to 250-350 $\mu \mathrm{s}$, the pulse energy was $4.0 \mathrm{~J} /$ pulse, the frequency was $5-8 \mathrm{~Hz}$, and the average power was 80 watts. The laser energy was delivered to the prepuce near contact using a delivery optical fiber. No cooling system was required during laser activation. In the conventional scalpel group, long-straight forceps were applied along the lower foreskin above the glans and the foreskin was excised by cutting below the forceps with a scalpel. Bleeding was stopped with electrocoagulation or ligation (Group 2, $n=40)$.

\section{Results}

Eighty-one patients were included in the study (Table 1). The average age of group 1 was 15.53 years old with a standard deviation of 7.35 , whereas the average of group 2 was 16.34 years old with a standard deviation of 9.22. Parts of the patients $(31 / 81,38.20 \%)$ had a preoperative diagnosis of phimosis. The other indications for circumcision were redundant prepuce and recurrent balanoposthitis. There was no statistically significant
Table 1 Comparison of clinical data for Holmium YAG laser circumcision versus conventional circumcision

\begin{tabular}{|c|c|c|c|}
\hline Variables & Group 1 & Group 2 & $p$ value \\
\hline Number of patients & 41 & 40 & \\
\hline Age (years) & $15.53 \pm 7.35$ & $16.34 \pm 9.22$ & 0.65 \\
\hline Indications & & & 0.78 \\
\hline Phimosis & 17 & 14 & \\
\hline Redundant prepuce & 13 & 16 & \\
\hline Recurrent balanoposthitis & 10 & 9 & \\
\hline Others & 1 & 1 & \\
\hline Operative time & $24.40 \pm 3.94$ & $27.25 \pm 4.35$ & $<0.01^{\#}$ \\
\hline Estimated blood loss (ml) & $4.68 \pm 2.52$ & $6.71 \pm 3.86$ & $0.03^{\#}$ \\
\hline Postoperative pain score & $2.20 \pm 1.18$ & $2.95 \pm 1.29$ & $0.05^{\#}$ \\
\hline Complications (total) & 3 & 10 & $<0.01^{\#}$ \\
\hline Edema & 1 & 5 & $<0.01^{\#}$ \\
\hline Hematoma & 1 & 3 & $<0.01^{\#}$ \\
\hline Persisting pain & 0 & 1 & 0.78 \\
\hline Infection & 1 & 1 & 0.22 \\
\hline Wound dehiscence & 0 & 0 & 1.00 \\
\hline Scarring & 0 & 0 & 1.00 \\
\hline
\end{tabular}

\# Significant difference

difference in the age distribution and indications between the two groups. The operative time was significantly shorter in group 1 than in group $2(24.40 \pm 3.94$ vs. $27.25 \pm 4.35 \mathrm{~min}, p<0.01)$. The estimated blood loss was also less in group 1 compared to group 2 . The complications were less in group 1 than in group 2 (3/41 vs. $10 / 40, p<0.01)$. The overall complication rate was $7.31 \%$ in group 1 and $25.00 \%$ in group 2 . In subgroup analysis, the most common complication in the study population was postoperative edema and local hematoma. There was also less local edema and fewer local hematomas in group 1. Patients reported less pain in group 1 than in group 2 and the VAS pain score reached a significant difference $(p=0.05)$. All patients tolerated the procedure without severe side effects.

\section{Discussion}

Circumcision is one of the most common urological procedures. Although circumcision is considered a minor procedure, patients carry a risk of complications, including local edema, local tenderness, hematoma, infection, wound dehiscence, and scarring [7-9]. The Holmium YAG laser has been reported to be effective for the treatment of soft tissue pathologies, such as Holmium laser enucleation of the prostate (HoLEP), upper tract urothelial carcinomas, and urinary strictures. The Holmium YAG laser has a short destruction length in the tissue due to strong absorption of water molecules around $2140 \mathrm{~nm}$. A penetration depth of $0.4 \mathrm{~mm}$ was reported, 
which allows coagulation and a vaporation-incision. It is considered suitable for an alternative laser technique for circumcision. Nonetheless, to our knowledge, there has been no evaluations of the efficacy and safety of Holmium laser circumcision. We first reported that there is a shorter operative time, less postoperative pain, less blood loss, and fewer complications among patients who underwent circumcision with Holmium YAG laser. These findings support it as a good choice for laser circumcision. Currently, carbon oxide lasers are widely used for circumcision due to its advantages. First, $\mathrm{a} \mathrm{CO}_{2}$ laser provides good incision and hemostasis ability because small vessels can be cauterized under a high-power setting. Second, the effectiveness of the incision is much better with a $\mathrm{CO}_{2}$ laser compared to the conventional scalpel method. Third, patients feel less postoperative pain compared to those treated with the conventional method, which increased the comfort of the patients. Several studies have supported these theses. Xu et al. stated that there were shorter operative times, less blood loss, and a lower postoperative complication rate in the laser group compared to the conventional group [3]. Mungnirandr et al. reported similar conclusions as well [10]. They found that the $\mathrm{CO}_{2}$ laser and tissue glue method were a good procedure with a significantly shorter operative time, lower proportion of tissue with local irritation, and good cosmetic appearance. Gorgulu et al. also stated that the combined $\mathrm{CO}_{2}$ laser and cyanoacrylate procedure not only decreased the operating time markedly, but also eliminated the disadvantages [11]. As for the Nd-YAG laser used in circumcision, George Vaos completed a trial with patients who underwent the guillotine circumcision procedure with a Nd-YAG laser (setting of 15-30 W and pulse duration of $0.2-0.5 \mathrm{~s}$ ) or conventional scalpel electrocoagulation [6]. He found fewer early and late complications in the Nd-YAG laser group but spent more time in the Nd-YAG laser group than in the conventional group.

To the best of our knowledge, the present study is the first to evaluate the efficacy and safety of circumcision using the Holmium YAG laser. A shorter operative time, less postoperative pain, less blood loss, and fewer complications were found. However, the cost of $\mathrm{CO}_{2}$ lasers is expensive for patients and medical providers. The cost of a laser device is about Singapore dollars $\$ 105,000$ (approximately equal to USD $\$ 75,124$ ). The maintenance charges are Singapore dollars $\$ 5000$ (approximately equal to USD \$3577) every year, and the predictable lifespan for each device is 10 years. Thus, the machine costs comprise Singapore dollars $\$ 15,500$ (approximately equal to USD $\$ 11,089)$ per year [12]. In a local hospital or clinic, there are estimated to be one hundred circumcisions per year, which makes the cost of the device per circumcision
Singapore dollars $\$ 155.0$ (approximately equal to USD $\$ 110.89$ ). Hence, the cost of a Holmium YAG laser per use is just USD $\$ 66.20$. Although this cost is more than the conventional scalpel method, the above finding is useful information for small capacity hospitals or clinics, and the Holmium YAG laser can be an alternative choice for laser circumcisions.

Another important issue widely discussed is the potential for sub-clinical injury by electrosurgery on the penis. Some studies have shown that conventional monopolar electrocoagulation may cause electrical burns, penile tissue damage, and necrosis [13-17]. Tsai et al. conducted an experiment that demonstrated the electrical field strength of the whole penis shaft was $9.03 \mathrm{~V} / \mathrm{cm}$. They found heat generated from the penis is four times that of other body parts, which may contribute to erectile tissue damage by heat [18]. They also suggested since they use less power $(\mathrm{W})$ and less time, bipolar electrosurgery, ligation to achieve hemostasis, and new laser technologies, including $\mathrm{CO}_{2}$, Nd-YAG or Holmium YAG laser, are superior methods.

\section{Conclusions}

In light of our study, we suggest that the use of a Holmium YAG laser in circumcision is a novel, less complicated, less painful, and easy procedure and may be considered as an alternative procedure for circumcision in young males.

\section{Abbreviations \\ Holmium YAG: Holmium: yttrium-aluminum-garnet; Nd-YAG: Neodymium: yttrium-aluminum-garnet; VAS: visual analog scale.}

\section{Acknowledgements \\ Not applicable.}

\section{Authors' contributions}

PLH and ICL contributed to data collection and analysis and manuscript writing. DCT and VFST contributed to idea suggestion and data analysis; JHT contributed to protocol development; YHP contributed to protocol development and revision and edited the final version of the manuscript. All authors read and approved the final manuscript.

\section{Funding}

This study had no funding from any resource.

\section{Availability of data and materials}

The datasets used and/or analyzed during the current study are available from the corresponding author on reasonable request.

\section{Ethics approval and consent to participate}

This retrospective study is approved by Ten Chen Hospital Institutional Review Board/Ethics Committee. (MA-04-02). Consent to participate is not applicable.

\section{Consent for publication}

Not applicable. (No photographs or patients' personal information were included in this retrospective diagnostic test accuracy study.) 


\section{Competing interests}

The authors declare that they have no competing interests.

\section{Author details}

${ }^{1}$ Department of Urology, Ten Chen Hospital, Taoyuan, Taiwan, ROC. ${ }^{2}$ Department of Urology, Ten Chan Hospital, Taoyuan, Taiwan, ROC.

Received: 28 July 2020 Accepted: 16 September 2020

Published online: 17 November 2020

\section{References}

1. Prabhakaran S, Ljuhar D, Coleman R et al (2018) Circumcision in the paediatric patient: a review of indications, technique and complications. J Paediatr Child Health 54:1299-1307

2. Raveenthiran $V$ (2018) The evolutionary saga of circumcision from a religious perspective. J Pediatr Surg 53:1440-1443

3. Xu Y, Li F, Li Z et al (2013) A prospective, randomized controlled trial of circumcision in adult males using the $\mathrm{CO}_{2}$ laser: modified technique compared with the conventional dorsal-slit technique. Photomed Laser Surg 31:422-427

4. Aynaud O, Casanova JM, Tranbaloc P (1995) $\mathrm{CO}_{2}$ laser for therapeutic circumcision in adults. Eur Urol 28:74-76

5. Washida H, Tsugaya M, Hirao N (1984) Experience using the laser rod in urological surgery. Hinyokika kiyo Acta urologica Japonica 30:891-896

6. Vaos G (2004) Circumcision with the Nd:YAG laser contact technique compared with conventional surgery. Photomed Laser Surg 22:318-322

7. Krill AJ, Palmer LS, Palmer JS (2011) Complications of circumcision. Sci World J 11:2458-2468

8. Weiss HA, Larke N, Halperin D et al (2010) Complications of circumcision in male neonates, infants and children: a systematic review. BMC Urol $10: 2$
9. Barrier G, Attia J, Mayer MN et al (1989) Measurement of post-operative pain and narcotic administration in infants using a new clinical scoring system. Intensive Care Med 15(Suppl 1):S37-S39

10. Mungnirandr A, Wiriyakamolphan S, Ruangtrakool R et al (2015) Comparison of a $\mathrm{CO}_{2}$ (carbon dioxide) laser and tissue glue with conventional surgical techniques in circumcision. J Lasers Med Sci 6:28-37

11. Gorgulu T, Olgun A, Torun M et al (2016) A fast, easy circumcision procedure combining a $\mathrm{CO}_{2}$ laser and cyanoacrylate adhesive: a non-randomized comparative trial. Int Braz J Urol Off J Braz Soc Urol 42:113-117

12. How AC, Ong CC, Jacobsen A et al (2003) Carbon dioxide laser circumcisions for children. Pediatr Surg Int 19:11-13

13. Gearhart JP, Rock JA (1989) Total ablation of the penis after circumcision with electrocautery: a method of management and long-term followup. J Urol 142:799-801

14. Hsu GL, Hsieh CH, Wen HS et al (2004) The effect of electrocoagulation on the sinusoids in the human penis. J Androl 25:954-959

15. Seleim HM, Elbarbary MM (2016) Major penile injuries as a result of cautery during newborn circumcision. J Pediatr Surg 51:1532-1537

16. Uzun G, Ozdemir Y, Eroglu M et al (2012) Electrocautery-induced gangrene of the glans penis in a child following circumcision. BMJ Case Rep 2012:1

17. Song LJ, Zhu JQ, Xie MK et al (2014) Electrocautery-induced cavernous nerve injury in rats that mimics radical prostatectomy in humans. BJU Int 114:133-139

18. Tsai VF, Chang HC, Liu SP et al (2010) Determination of human penile electrical resistance and implication on safety for electrosurgery of penis. J Sex Med 7:2891-2898

\section{Publisher's Note}

Springer Nature remains neutral with regard to jurisdictional claims in published maps and institutional affiliations.

\section{Submit your manuscript to a SpringerOpen ${ }^{\circ}$ journal and benefit from:}

- Convenient online submission

- Rigorous peer review

- Open access: articles freely available online

- High visibility within the field

- Retaining the copyright to your article

Submit your next manuscript at $\boldsymbol{\nabla}$ springeropen.com 